\title{
Absence of verbal recall or memory for symptom acquisition in fear and trauma exposure: A conceptual case for fear conditioning and learned nonuse in assessment and treatment
}

\author{
A. Ronald Seifert, PhD \\ Licensed Psychologist, Silverdale, WA
}

\begin{abstract}
Absence of memory or verbal recall for symptom acquisition in fear and trauma exposure, as well as absence of successful coping behavior for life events, is associated with a number of diagnoses, including traumatic brain injury, posttraumatic stress disorder, pain, and anxiety. The difficulty with diagnosis and treatment planning based on the absence of recall, memory, and successful coping behavior is threefold: (1) these assessments do not distinguish between disruption of behavior and lack of capacity, (2) the absence of verbal recall and memory complicates cognitive-based treatment, and (3) a confounding issue is the same absent behavior can be observed at different times and contexts. While memory of the specific details of the initial traumatic event(s) may not be available to verbal report, the existence of time- and context-dependent relationships for the initial as well as subsequent experiences is arguable. The absence of memory or lack of verbal recall does not rule out measurable physiological bodily responses for the initial trauma(s), nor does it help to establish the effects of subsequent experiences for symptom expression. Also, the absence of memory must include the prospect of fear-based learning that does not require or involve the cortex. It is posited that the literatures of fear conditioning and learned nonuse provide complementary illustrations of how the time and context of the initial trauma(s) and subsequent experiences affect behavior, which is not dependent on the effected individual being able to provide a memory-based verbal report. The replicated clinical application demonstrates that, without scientific demonstration, neither neuroanatomy nor verbal report can be assumed sufficient to predict overt behavior or physiologic responses. For example, while commonly assumed to be predictively so, autonomic nervous system innervation is insufficient to define the unique stimulus- and context-dependent physiological responses of an individual. By recording simulta-
\end{abstract}

neous physiological responses to the controlled presentation of a context-dependent stimulus, the unique relationships of physiology and overt behaviors for the individual can be demonstrated. Using this process also allows more complex virtual reality or other in vivo stimulus assessments to be incorporated for the development of individually tailored assessments and therapeutic plans. Thus, with or without memory or verbal recall, the use of multiple time- and context-specific simultaneous physiological measures and overt behavior can guide clinical effort as well as serve to objectively assess the ongoing treatment and its outcome.

Key words: anxiety, context learning, fear conditioning, learned nonuse, memory, pain, physiology, posttraumatic stress disorder, traumatic brain injury, verbal recall.

\footnotetext{
Abbreviations: ANS $=$ autonomic nervous system, $\mathrm{CBT}=$ cognitive behavioral therapy, CIMT $=$ constraint-induced movement therapy, $\mathrm{CR}=$ conditioned response, $\mathrm{PNS}=$ parasympathetic nervous system, PTSD = posttraumatic stress disorder, REM = rapid eye movement, $\mathrm{SNS}=$ sympathetic nervous system, $\mathrm{TBI}=$ traumatic brain injury.

Address all correspondence to A. Ronald Seifert, PhD; 13948 Sunrise Dr NE, Bainbridge Island, WA 98110; 206619-5661; fax: 360-308-0447. Email: ronseifert@msn.com http://dx.doi.org/10.1682/JRRD.2011.11.0214
} 


\section{INTRODUCTION}

The absence of memory or verbal recall for symptom acquisition, as well as the absence of successful coping for life events, is associated with a number of diagnoses, including traumatic brain injury (TBI), posttraumatic stress disorder (PTSD), pain, and anxiety. Including the "absence of behavior" in the reasoning for assignment of such diagnoses can be important to the description of prior existing conditions, especially if a method of measuring it is outlined. However, while of possible diagnostic importance, the absence of behavior is nonquantifiable and does not address the significant issue of whether absence is because of the disruption or incapacity for behavior. A focus on the absence of behavior potentially introduces a further issue by treating nonobserved and observed behaviors equally.

Confounding any effort is that assessment and treatment planning for highly variable events are not conducted at the time or context of the trauma(s). Therefore, such efforts must be undertaken without the benefit of being able to objectively differentiate the effects of the original and subsequent experiences on the current state [1-2]. Notably, the absence of verbal recall or memory of the initial trauma(s) does not preclude subsequent experiences from being remembered or having an effect on symptom expression. In addition, not having access to the individual's cognitive and emotional capabilities over the same time and context precludes measuring any variation and possible effect. The continuous process of the individual's attempts for adaptation introduces additional timeand context-dependent based efforts that can affect behavior in highly variable ways. Knowing these factors would provide both a historical and contemporary perspective of how the process affects an individual's current functional state [3].

Further complicating the process of attempting to document the effect of trauma is that the noted absence of behavior is commonly attributed to multiple causative explanations that include genes, "failure to learn," motivation, and neurological damage, all of which can affect prospective considerations for treatment. Genes take on a seemingly irrefutable power, even in the absence of the scientific demonstration of cause and effect. Often overlooked is that possessing the genetic characteristic does not determine the effect, as in the case of the gene associated with alcoholism, which still requires an individual to drink to sufficient excess. Parenthetically, alcoholism can occur without the requisite gene. Additionally, the fact that one monozygotic twin can develop normally and the other be diagnosed as autistic makes an effective case for consideration of additional contributing factors. Similarly, the attribution of failure to learn avoids the question of whether such failure is caused by lack of adequate training. The inferred and assigned construct "lack of motivation" further obscures the failure to improve by blaming the person being treated. Also widely assumed is that neural trauma of a known anatomical structure is sufficient reason not only for the absence but also for the prediction of recovery of behavior [4]. A conceptual model based on known scientific evidence would be beneficial so as to avoid resorting to the use of absence of behavior and potentially engaging in circular logic and self-fulfilling prophecy. The potential for doing no harm can also be improved on.

\section{METHODS}

Existing replicated scientific literature was reviewed for clinical applicability to the aforementioned conditions. The scientific-based relationships for structure and function, the relationship of environmental- and timebased influences on learning, and the presence or absence of declarative memory in fear- and trauma-based symptom acquisition was considered. Two areas of research, fear conditioning and learned nonuse theory, provided substantive findings addressing these criteria.

A recent publication by Arzi et al. demonstrates learning during sleep [5]. Elicitation of the conditioned responses (CRs) in the nonsleep state is specific to the sleep stage present during training. Absence of verbal recall during the nonsleep state did not prevent successful demonstration of sleep-based learning. The premise that learning can be demonstrated to occur without awareness or verbal recall is supported. Bodily responses can be used to demonstrate such phenomenon, and clinical application can be developed to address the relevant time and context parameters.

Fear conditioning research provides an emotionbased relationship for stimulus-specific acquisition and retention of learned behavior in mammals. The classic [6] conditioning paradigm has been reliably demonstrated across a wide range of species, including primates [7]. Placing a rat in a box with an electrified grid that can be turned on and off illustrates this paradigm. A slight tone 
is sounded preceding the onset of shock. Recall that slight variations in the timing of the involved stimuli are scientifically demonstrated to have profound effect on the learning process. In this instance, learning is demonstrated when the rat responds to the sound stimulus and escapes as it previously did to the shock. Animals quickly learn and retain this behavior.

Extensive scientific studies of fear conditioning across many species have been carried out, including histologically verified ablations to determine the involvement of specific brain areas in learning and memory, electrophysiological recordings documenting both the time and sequence of specific brain area response, and chemical blocking agents that reduce or eliminate specific kinds of neural activity in a related brain area [8]. The results from these multifaceted replicated research studies have established relationships for specific areas of the brain and their effect on acquisition or retention of fear conditioning [7,9-15]. Learning and memory for single-cue fear conditioning does not require cortical involvement [16-18]. Also, fear-conditioned learning occurs very quickly via specific amygdala and thalamic subcortical pathways activating the hypothalamic and autonomic nervous systems (ANS) with associated organ responses [19]. Such organ responses to fear reflect a primary emotion, providing survival benefit throughout the life span. For instance, when walking along a pathway, a noncortically mediated response to what looks like a snake leads to the startle response and escape. The cortex can then determine whether the object was a snake or not. True, people may react to more false alarms, but there will also be fewer snake bites.

Learned nonuse research addresses how damage to neural structure, the passage of time, and environmental context can affect behavior. It also provides an elegant demonstration of the need for caution in interpreting the role structure plays in function and behavior. Reciprocally, the use of behavior to infer the contributing structure requires equal caution. Existing beliefs for the function of known neural systems are further challenged by simultaneous measurement of physiological responses specific to time and context.

For over 75 years, the unilateral surgical deafferentation of the upper limb in the monkey [4], with its subsequent absence of purposeful use of that limb, was dogmatically presented as proof of the relationship between afferent innervation and behavior. Based on absence of behavior, the observed conditional relation- ship was then confounded by the use of illogical biconditional reasoning that recovery could not be gained and seeking other explanation need not be undertaken.

The belief persisted until Taub [20] scientifically demonstrated that bilateral surgical deafferentation of the upper limbs in the monkey did not result in the same loss of purposeful use, as did unilateral deafferentation [21-22]. Specifically, loss of innervation to one upper limb led to loss of function, while the loss of innervation to both upper limbs did not. Furthermore, prenatal and perinatal somatosensory unilateral deafferentation did not result in the same loss of function as with the adult monkey [23]. The surgically sectioned sensory and afferent pathways of the upper limbs, unilateral and bilateral, were histologically verified, providing scientific demonstration of the insufficiency of the explanation based on neuroanatomy and absence of behavior.

It is widely accepted that behavior involves more than the connecting neural pathways, along with the belief that function cannot occur without the connecting sensory pathways. Taub's research did not disprove all relationships between anatomy and function, but it did confront the existing belief that anatomy is a sufficient explanation for behavior. The relationships between anatomy and behavior must be scientifically proven and not based on belief, even strongly held beliefs.

Through multiple elegant and innovative experimental demonstrations, the absence of purposeful behavior following unilateral deafferentation was attributed to postsurgical learned nonuse [20,24-28]. Supporting this hypothesis, Taub and Goldberg demonstrated that lack of recovery of purposeful behavior involved both time- and context-dependent learning [29]. Contributing to this demonstration and understanding was that restricted use of the unilaterally deafferented limb during the postsurgical shock period resulted in some spontaneous recovery of function [3]. A caveat is that the spontaneous recovery following the postsurgical restraint did not achieve results as great as were demonstrated following the development of the behavior training method constraintinduced movement therapy (CIMT) [3].

\section{RESULTS AND DISCUSSION}

CIMT demonstrated that time-delayed restraint of the nonsurgical limb during behavior training of the unilateral surgically deafferented limb led to the recovery of 
purposeful use in monkeys [23,29-30] and in humans after stroke [31]. In some cases, the CIMT achieved voluntary purposeful behavior consistent with presurgical limb function, providing further support for Taub's hypothesis of learned nonuse. While early human clinical research focused on the use of CIMT following stroke $[20,25]$, a series of internationally funded scientific studies subsequently demonstrated applicability following other traumas, including upper limbs after TBI, lower limbs after stroke, spinal cord injury, fractured hip, and aphasia after stroke [32-37].

The demonstration of time- and context-dependent learned nonuse is critical to Taub's research. Restricting postsurgical limb use during the postsurgical shock period led to some spontaneous recovery. This finding has been of limited benefit because while restricting the use of a deafferented limb is experimentally controllable, knowing how long to prevent use is problematic because the postsurgical shock period can vary widely across individuals [3]. Again, the absence of behavior does not provide a meaningful way to determine the end of the postsurgical shock period or when to allow voluntary limb use in the spontaneous recovery process. What remains clear is that the surgically induced neurological trauma with the immediate attempted postsurgical use led to decreased spontaneous recovery of behavior. The resulting absence of behavior had previously limited treatment expectations for recovery of limb function until the demonstration of learned nonuse. Complicating spontaneous trauma and fear experiences are the absence of precisely induced neurologic injury; possible and probable multiple contributing injuries; unknown time and context variables that affect learning; specific results for such experiences; and singular reliance on memory and verbal recall of those factors for diagnosis, assessment, and treatment. Furthermore, as with stroke and training for the substituted use of the nonaffected limb, treatment efforts following trauma(s) can interfere with regaining function. Until additional research can provide greater clarification, incorporating existing knowledge for learned nonuse and CIMT can conceptually broaden and benefit treatment efforts while avoiding potential harm.

The evolution of scientific research for fear conditioning and learned nonuse illustrates the benefit of and need for increased elucidation of the complex effect(s) of time- and context-dependent variables on all behavior $[1-3,7]$. Surely of benefit to assessment and treatment planning would be a detailed time- and context-based history for all events associated with the trauma and the subsequent courses of action [2]. In support of the effect of time and context on learning and its relevance to our present scientific and clinical understanding is the demonstration of a continuum for mammalian responses, which is not restricted to observable overt behavior $[8,38]$. For instance, a single cell as well as multiple cells can be trained to respond conditionally [16]. Such demonstrations do not tell us why there is a response, nor do they necessarily provide answers for the absence of response when observing across levels of response, cellular to overt behavior. However, the utilized training processes do reliably establish the relevant time and context variables that affect the parameters for acquisition of the response across these various levels. Taub's innovative and highly awarded collective research demonstrated that time and context can affect both the absence and presence of behaviors leading to very different conclusions. These conclusions were not straightforward and could not be automatically assumed based on genetics, anatomy, theoretical concepts, or beliefs. Scientific verification increases the probability that the critical questions are asked and that any possible harm is avoided [39].

Thus, fear conditioning provides scientific demonstration of time- and context-dependent behavior both for CRs that are hardwired in [40] and those that occur before involvement of the cortex [7]. Learned nonuse provides specific illustration that surgically induced sensory neurological damage did not predict recovery of behavior. It is probable that one or the combination of these literatures can be applied in the demonstration of individually specific physiologic effects reflective of the initial trauma(s) and fear, as well as of subsequent experiences and behavior. Until recently, the diagnosis of PTSD, a condition that can involve fear and trauma, was excluded when there was an absence of memory for the actual traumatic event(s). The absence of memory was challenged for multiple reasons, including that it does not disprove that precipitating traumatic events occurred, that subsequent events do affect the condition and memory, and the fact that this phenomenon is both not unusual and commonly observed in clinical practice [41]. While representing greater inclusion for clinical diagnosis, this theoretical reformulation did not address or resolve the issue of whether absence of memory for traumatic events is based on lack of verbal recall, incapacity to remember, or possible misinformation. 
Another unresolved issue for improved understanding of the effects of trauma, especially when it occurs on the battlefield, is that systematic recording of the time and context of traumatic events does not occur. Neither is there agreed upon or consistently utilized nomenclature for recording and establishing what constitutes fear- and trauma-based events [2]. Thus, relative factors that could benefit assessment and treatment planning are limited or lost. Also, collaborative observers are rarely available to provide any firsthand detail of the traumatic events. When they are, they too can experience similar problems that affect their verbal recall and memory. Even when these individuals experienced no trauma, the opportunity to interview them is usually time-delayed and out of context. The literature for recall of memories provides caveat for great caution no matter the circumstance. These limitations and an extensive literature for identifying triggering stimuli that affect physiologic responses make a strong case for the combined use of physiological and overt behavior measures. Stimulus-specific physiological and overt behavior responses have been recorded for a wide range of individuals, from athletic peak performance to numerous diagnoses including traumatic events [34,4243]. However, such an effort must be implemented with great consideration. One consideration is that controlled studies with time- and context-dependent averaged responses are typically seen. Averaging removes the physiological variability of the individually unique and critical response patterns that are used to demonstrate the time and context relationships for behavior.

While individually specific physiological measures provide an objective means to address the effects associated with human trauma(s) and fear, how the process is conducted and what is measured requires considering some critical issues. The classical teaching of physiological response based on neural pathways, implying that the innervation is sufficient to predict behavior, is significant. For instance, it is commonly assumed that the sympathetic nervous system (SNS) and parasympathetic nervous system (PNS) branches of the ANS respond uniformly to a common stimulus across individuals. Typically not taught is that, in humans, known SNS and PNS innervation does not preclude objectively measured physiological responses that are inconsistent with such beliefs [44-45]. Over 30 years of multiple personally conducted, computer-based physiologic measures of human responses demonstrate that individual patterns of response not only occur but are common. Furthermore, confounding our understanding are analyses of past research that are based on assumptions inconsistent with more recent multidisciplinary research demonstrating that cardiovascular and respiratory function can be affected by three, not two, neurological pathways [4652]. The newer findings affect many prior studies that infer ANS-based measures without neurophysiological differentiation as to whether the overt behavior represented "freeze," "fight or flight," or "relaxation." What confounds understanding for such a relationship is that, as illustrated by the fear conditioning research, the cortex need not be involved for there to be physiologic response(s). Animal studies of time-series recordings indicate that the amygdala, limbic system, and downstream organ responses occur before the cortex is involved. Adding to the problem is that in fear conditioning, CRs do not differentiate those elicited by the conditioned stimulus and those acquired through learning [7]. Specifically, how can it be known whether an overt behavior is cognitively mediated? Again, objective recordings provide a means to move beyond inferred assumptions or beliefs that are not based in science.

What remains reliable is that patterns of physiologic response can be observed both with and without the individual's awareness of their response(s). When recording is conducted without the individual knowing what is being recorded, their verbal report is usually inaccurate for the response or its direction. Most often, he or she verbally reports that he or she does not know and is unable to determine the answer to such question(s). Some individuals guess more accurately but do so without great confidence in their answer. Clearly, verbal recall alone is insufficient to establish the veracity of the individual's physiologic response. Parenthetically, prediction of physiologic response(s) based on overt behavior is no more reliably predicted by an observer. What can be demonstrated and is of importance is that whether the individual or the observer knows "whether" or "what" response has occurred does not prevent time- and contextual-based stimulus-response relationships from being objectively established [53-54]. The simultaneous measurement of multiple physiological measures is required to demonstrate such complex phenomena. That the individual's responses can vary for specific stimuli and contexts reinforces the need for multiple repeated systematic physiological measurements [44-55]. Such multiple objective measures provide a truly efficacious means to identify individual responses to a given stimulus, both within and 
across contexts. Thus, the false rejection of existing stimulus-response relationships that is based on a single physiologic measure is avoided. Such response variations are not unique or restricted to those individuals with traumaor fear-based histories. Simply put, neural pathways, including those for the ANS, are insufficient to predict individual physiological organ response to stimulus, within or across contexts. Thus, recording multiple timeand context-specific physiologic stimulus measures provides greater objectivity for both assessment and treatment. The benefits of establishing multiple objectively recorded physiological measures seem straightforward. What is hoped for is that the obvious benefit of these measures moves assessment and treatment conceptualization beyond reliance on the absence of behavior.

Arguable for consideration and adaptation in clinical application is the process of systematic desensitization [56]. It is acknowledged that treatment of simple phobia can succeed without the individual knowing or the therapist being required to determine the memory for the acquisition of such fear. However, a limitation of systematic desensitization is that overt behavioral response typically used to establish the phobia as well as the treatment effect does not reliably predict any associated physiologic response(s). Therefore, this and similar approaches based solely on overt behavior are insufficient in the assessment and treatment of TBI, PTSD, pain, and anxiety for multiple reasons. First, any trauma- or fear-based absence of response is not measurable through observation of overt behavior. Second, overt behavior is not adequate to infer unmeasured nonrecorded physiological response. Third, nonrecorded physiologic measures can occur in directions unpredictable based on overt behavioral response. Fourth, behavior response is no more sufficient to predict physiology than physiology is to predict overt behavior. Simply put, standing motionless in response to a stimulus can be either a behavior inferred to be a calm non-SNS arousal or a freeze response associated with high arousal mediated via non-ANS pathways [46-52].

While procedures for training of overt behavior are widely known, the procedures for training for successful self-regulation of physiology are not as widely known or used. Such control of physiological response has been repeatedly demonstrated for nonhumans and humans using established training procedures. In nonhuman research, such change is often accomplished using some stimulus-response procedure to demonstrate change in the desired direction. For humans, other established procedures for training of learned objectively demonstrated response are used and published. However, the training procedures do not establish how an individual learns selfregulation of physiological control. Additionally, the numbers of required training trials can and will likely vary across individuals. Successful training is not determined by some predetermined number of trials but as an objectively demonstrated competency. Note that research designs based on the same number of training trials for each participant to test the effect of learned physiological self-control for a designated symptom benefit are inherently faulty and misleading. In such cases, what is tested is whether all individuals learn equally for the same number of training trials. Training to objective competency demonstrated by differential physiological self-control is required before comparison can be made for any symptom benefit. As previously noted, it is frequently observed that, during self-control training for one physiological measure, there can be spontaneous changes in other measures. Again, these spontaneous shifts often occur in the opposite direction as predicted by neuroanatomical innervation.

In addition to demonstrated learned self-regulation of physiology by nontraumatically affected individuals, those with lower intelligence quotient scores, brain damage, and other trauma have learned control of specific physiological response associated with symptom change in the desired direction. These include the differential control of electroencephalography to reduce medically unresponsive epileptic seizures [57-58] and other conditions [59], as well as the aforementioned training and recovery of affected limbs following stroke [3], the upper limbs after TBI, the lower limbs after stroke, spinal cord injury, fractured hip, and aphasia after stroke [33-37]. What has also been demonstrated is that the presence of verbal report or lack of memory does not determine whether voluntary control of physiological response can be trained. Parenthetically, trained differential self-control (increase or decrease) of physiological response to the same cue has also been demonstrated. This training can and often does occur with the individual sitting quietly in a reclining chair. Again, observation of the individual sitting quietly does not allow accurate prediction of the physiological responses. Redundantly, assessment and clinical therapies based solely on the presence or absence of verbal report or overt behavior do not account for these possibilities. Therefore, observed overt behavioral 
response without objective physiological measures can miss the mark for multiple reasons, including time, context, adaptation, and method of measurement. Assumption based solely on patient motivation should evoke even greater caution.

Without additional objective measures, what still remains unanswered is whether an absence of behavior is because of a disruption or lack of capacity, with or without trauma. Whether the cortex was involved in the response to the initial and/or any subsequent traumatic stimuli is also not determined. Taub's devised CIMT training obtained beneficial therapeutic results without answers to these questions. It is plausible that the benefit of such simultaneous objective measurement of overt behavior and physiological responses would include a more objectively based understanding of the probable mind and body interactions [60]. It is encouraging that by incorporating both physiologic and overt behavior, with or without awareness, the capacity for training self-control of physiological response can be used to address the probable stimuli associated with symptom acquisition and subsequent experience. Such learning can have powerful influence on the individual's present and future behavior.

\section{CONCLUSIONS}

Without including both overt behavior and physiological responses in assessment and treatment planning, reports of success for cognitive behavioral therapies (CBTs) based conceptually on "toughing it out" are of concern. The history of "flooding," "immersion," and "implosion" therapies for phobia extinction that involve facing one's fear until no longer fearful are examples of such logical strategies. Historically, the effectiveness and merit of such efforts are not without controversy [61-62]. Even when an individual is able to remain in the feared context until they no longer report being afraid, his or her verbal report does not provide objective demonstration of anticipated physiological benefit, nor does it demonstrate that there was no adverse effect on physiology [46-52]. It is obvious that an assumed relationship between cognition, physiology, and overt behavior cannot be used both as the basis for such treatments and as rejection of the need for physiological measurement to verify any treatment effect. As with absence of behavior, the nonmeasured physiological responses reflect unknowns and cannot be used to infer positive or rule out negative effect on physiology, health, or overt behavior [63]. Modifying CBT procedures to incorporate objective assessment and treatment based on time- and context-dependent physiological measures to address these concerns for the unknown would seem desirable [39].

Similarly, teaching cognitive control for "mindfulness” infers physiological benefit. Again, verbal report and overt behavior are inadequate to infer context-specific physiological responses. As previously noted, overt behavior can represent one thing to an observer and a totally different experience for the individual. How does one differentiate whether the overt behavior of standing motionless in the presence of a known fear-triggering stimulus reflects fight or flight, relaxation, or freeze response physiology? It is compelling that these responses can appear similar but represent very different physiological states mediated via different areas of brain and neurological pathways [47-52]. Such distinctions are not irrelevant or inconsequential for training adaptation to environmental demand, health, or longevity. Failing to address such distinction stops clinicians from providing the most meaningful guidance in assessment, planning, or selection of treatment. More problematic is there likely will be decreased confidence for "doing no harm."

Adaptation in life is never-ending and cannot be defined without time- and context-referenced measure. Establishing an objectively determined relationship of an individual's response to the presentation of known stimulus based on multiple levels of objective measures of overt and physiologic behavior provides a more inclusive and represented process. Once identified, the opportunity exists to use this information to develop individualized therapeutic strategies that address the unknown and complex conditions of TBI, PTSD, pain, and anxiety with or without memory of fear and/or trauma(s). These same procedures can be used to establish an objective measure of an individual's ongoing treatment process. In addition, they provide for the assessment of treatment outcome as well as information to be used for developing future therapeutic efforts [64]. Use of such a model can help to avoid relying on assumptions that are believed to be true, even widely believed, but are not based in science.

The difficulty with diagnosis, assessment, and treatment planning based on absence of verbal report, memory, and successful coping behavior for life events is threefold: (1) these assessments do not distinguish between disruption of behavior and lack of capacity, (2) the absence of verbal recall and memory complicates cognitive-based treatment, and (3) a confounding issue is 
that the same absent behavior can be observed at different times and contexts. Further complicating the process are changes in cognitive status that affect experience across time and context that can differentially affect current and future response. Learned nonuse provides objective scientific understanding for why assumption based on neural pathway is insufficient to establish the specific relationships between fear, trauma, and subsequent behavior. Fear conditioning provides objective scientific demonstration of learning without the cortex. Trace conditioning during sleep demonstrates human learning during rapid eye movement (REM) and non-REM sleep as well as differential expression of that learning during nonsleep. It is demonstrated that inference serves as a poor substitute for objective physiologic measurements, specific to time and context. In addition, the objective results may benefit future treatment efforts, as with CIMT. The preparation and possible inoculation of others, who may become exposed to similar trauma- and fear-based contexts, can also benefit. More importantly, such an approach does not require reliance on absence of behavior or nonscientific explanations.

\section{ACKNOWLEDGMENTS}

Financial Disclosures: The author has declared that no competing interests exist.

Funding/Support: This material was unfunded at the time of manuscript preparation.

\section{REFERENCES}

1. Barrett LF, Mesquita B, Gendron M. Context in emotion perception. Curr Dir Psychol Sci. 2011;20(5):286-90. http://dx.doi.org/10.1177/0963721411422522

2. Carlson K, Kehle S, Meis L. The assessment and treatment of individuals with history of traumatic brain injury and post-traumatic stress disorder: A systematic review of the evidence. Washington (DC): Department of Veteran Affairs, Health Services Research and Development Service; 2009.

3. Taub E. Overcoming learned nonuse: A new approach to treatment in physical medicine. In: Carlson JG, Seifert AR, Birbaumer N, editors. Clinical applied psychophysiology. New York (NY): Plenum Press; 1994. p. 185-222.

4. Mott FW, Sherrington CS. Experiments upon the influence of sensory nerves upon movement and nutrition of the limbs. Proc R Soc Lond. 1895;57(340-46):481-88.

http://dx.doi.org/10.1098/rspl.1894.0179

5. Arzi A, Shedlesky L, Ben-Shaul M, Nasser K, Oksenberg A, Hairston IS, Sobel N. Humans can learn new information during sleep. Nat Neurosci. 2012;15(10):1460-65. [PMID:22922782]

http://dx.doi.org/10.1038/nn.3193

6. Pavlov IV, Anrep GV. Conditioned reflexes; An investigation of the physiological activity of the cerebral cortex. London (England): Oxford University Press; 1927.

7. LeDoux JE. In search of an emotional system in the brain: Leaping from fear to emotion and consciousness. In: Gazzaniga MS, Bizzi E, editors. The cognitive neurosciences. Cambridge (MA): MIT Press; 1995. p. 1049-61.

8. Knight DC, Smith CN, Cheng DT, Stein EA, Helmstetter FJ. Amygdala and hippocampal activity during acquisition and extinction of human fear conditioning. Cogn Affect Behav Neurosci. 2004;4(3):317-25. [PMID:15535167] http://dx.doi.org/10.3758/CABN.4.3.317

9. Bloom FE. Cellular mechanisms active in emotion. In: Gazzaniga MS, Bizzi E, editors. The cognitive neurosciences. Cambridge (MA): MIT Press; 1995. p. 1063-70.

10. Gazzaniga MS, Ivry RB, Mangun GR. Emotion. In: Gazzaniga MS, Ivry RB, Mangun GR, editors. Cognitive neuroscience: The biology of the mind. 3rd ed. New York (NY): W. W. Norton; 2009. p. 364-87.

11. Gray JA. A model of the limbic system and basal ganglia: Applications to anxiety and schizophrenia. In: Gazzaniga MS, Bizzi E, editors. The cognitive neurosciences. Cambridge (MA): MIT Press; 1995. p. 1065-76.

12. Halgren E, Marinkovic K. Neurophysiological networks integrating human emotions. In: Gazzaniga MS, Bizzi E, editors. The cognitive neurosciences. Cambridge (MA): MIT Press; 1995. p. 1137-51.

13. McEwen BS. Stressful experience, brain, and emotions: Developmental, genetic, and hormonal influences. In: Gazzaniga MS, Bizzi E, editors. The cognitive neurosciences. Cambridge (MA): MIT Press; 1995. p. 1117-35.

14. Rolls ET. A theory of emotion and consciousness, and its application to understanding the neural basis of emotion. In: Gazzaniga MS, Bizzi E, editors. The cognitive neurosciences. Cambridge (MA): MIT Press; 1995. p. 1091-1106.

15. Weinberger NM. Retuning the brain by fear conditioning. In: Gazzaniga MS, Bizzi E, editors. The cognitive neurosciences. Cambridge (MA): MIT Press; 1995. p. 1071-89.

16. Berger TW, Rinaldi PC, Weisz DJ, Thompson RF. Singleunit analysis of different hippocampal cell types during classical conditioning of rabbit nictitating membrane response. J Neurophysiol. 1983;50(5):1197-1219. [PMID:6644367]

17. Gupta A. Unconscious amygdalar fear conditioning in a subset of chronic fatigue syndrome patients. Med Hypotheses. 
2002;59(6):727-35. [PMID:12445517]

http://dx.doi.org/10.1016/S0306-9877(02)00321-3

18. Morris JS, Ohman A, Dolan RJ. A subcortical pathway to the right amygdala mediating "unseen" fear. Proc Natl Acad Sci U S A. 1999;96(4):1680-85. [PMID:9990084] http://dx.doi.org/10.1073/pnas.96.4.1680

19. Sah P, Faber ES, Lopez De Armentia M, Power J. The amygdaloid complex: anatomy and physiology. Physiol Rev. 2003;83(3):803-34. [PMID:12843409]

20. Taub E. Movement in nonhuman primates deprived of somatosensory feedback. Exerc Sport Sci Rev. 1976;4:335-74. [PMID:828579] http://dx.doi.org/10.1249/00003677-197600040-00012

21. Ince LP. Escape and avoidance conditioning of response in the plegic arm of stroke patients: A preliminary study. Psychon Sci. 1969;16:49-50.

22. Knapp HD, Taub E, Berman AJ. Movements in monkeys with deafferented forelimbs. Exp Neurol. 1963;7:305-15. [PMID:14033714] http://dx.doi.org/10.1016/0014-4886(63)90077-3

23. Taub E, Perrella PN, Miller EA, Barro G. Diminution of early environmental control through perinatal and prenatal somatosensory deafferentation. Biol Psychiatry. 1975; 10(6):609-26. [PMID:811268]

24. Braun C, Schweizer R, Elbert T, Birbaumer N, Taub E. Differential activation in somatosensory cortex for different discrimination tasks. J Neurosci. 2000;20(1):446-50. [PMID:10627620]

25. Taub E. Somatosensory deafferentation research with monkeys: Implications for rehabilitation medicine. In: Ince LP, editor. Behavioral psychology in rehabilitation medicine: Clinical applications. Baltimore (MD): Williams \& Wilkins Co; 1980. p. 371-401.

26. Taub E, Berman AJ. Avoidance conditioning in the absence of relevant proprioceptive and exteroceptive feedback. J Comp Physiol Psychol. 1963;56:1012-16.

[PMID:14100937]

http://dx.doi.org/10.1037/h0048315

27. Taub E, Berman AJ. Movement and learning in the absence of sensory feedback. In: Freeman SJ, editor. The neuropsychology of spatially oriented behavior. Homewood (IL): Dorsey Press; 1968. p. 173-92.

28. Taub E, Crago JE, Burgio LD, Groomes TE, Cook EW 3rd, DeLuca SC, Miller NE. An operant approach to rehabilitation medicine: overcoming learned nonuse by shaping. J Exp Anal Behav. 1994;61(2):281-93. [PMID:8169577] http://dx.doi.org/10.1901/jeab.1994.61-281

29. Taub E, Goldberg LA. Prism adaptation: control of intermanual transfer by distribution of practice. Science. 1973; 180(4087):755-57. [PMID:4702574] http://dx.doi.org/10.1126/science.180.4087.755
30. Taub E, Goldberg IA, Taub PB. Deafferentation in monkeys: pointing at a target without visual feedback. Exp Neurol. 1975;46(1):178-86. [PMID:1109336] http://dx.doi.org/10.1016/0014-4886(75)90040-0

31. Taub E, Miller NE, Novack TA, Cook EW 3rd, Fleming WC, Nepomuceno CS, Connell JS, Crago JE. Technique to improve chronic motor deficit after stroke. Arch Phys Med Rehabil. 1993;74(4):347-54. [PMID:8466415]

32. Birbaumer N, Lutzenberger W, Montoya P, Larbig W, Unertl K, Töpfner S, Grodd W, Taub E, Flor H. Effects of regional anesthesia on phantom limb pain are mirrored in changes in cortical reorganization. J Neurosci. 1997;17(14): 5503-8. [PMID:9204932]

33. Candia V, Schäfer T, Taub E, Rau H, Altenmüller E, Rockstroh B, Elbert T. Sensory motor retuning: a behavioral treatment for focal hand dystonia of pianists and guitarists. Arch Phys Med Rehabil. 2002;83(10):1342-48.

[PMID:12370865]

http://dx.doi.org/10.1053/apmr.2002.35094

34. Desai V. Report on functional utility score change in nine chronic stroke or closed head injury patients receiving a training program for overcoming learned nonuse as part of a multimodality treatment program. In: Miller NE, chair. Overcoming learned nonuse and the release of covert behavior as a new approach to physical medicine. Meeting of the Association of Applied Psychophysiology and Biofeedback; 1991; Dallas, TX.

35. Elbert T, Pantev C, Wienbruch C, Rockstroh B, Taub E. Increased cortical representation of the fingers of the left hand in string players. Science. 1995;270(5234):305-7. [PMID:7569982] http://dx.doi.org/10.1126/science.270.5234.305

36. Morris DM, Taub E, Uswatte G. Making gains: Constraintinduced movement therapy can improve motor function in people with TBI. ADVANCE. 2003;12(10):51-54.

37. Shaw SE, Morris DM, Uswatte G, McKay S, Meythaler JM, Taub E. Constraint-induced movement therapy for recovery of upper-limb function following traumatic brain injury. J Rehabil Res Dev. 2005;42(6):769-78.

[PMID:16680614]

http://dx.doi.org/10.1682/JRRD.2005.06.0094

38. Ader R, editor. Psychoneuroimmunology. 4th ed. Boston (MA): Elsevier/Academic Press; 2007.

39. Liepert J, Bauder H, Wolfgang HR, Miltner WH, Taub E, Weiller C. Treatment-induced cortical reorganization after stroke in humans. Stroke. 2000;31(6):1210-16.

[PMID:10835434]

http://dx.doi.org/10.1161/01.STR.31.6.1210

40. Blanchard DC, Blanchard RJ. Innate and conditioned reactions to threat in rats with amygdaloid lesions. J Comp Physiol Psychol. 1972;81(2):281-90. [PMID:5084445] http://dx.doi.org/10.1037/h0033521 
41. Rubin DC, Berntsen D, Bohni MK. A memory-based model of posttraumatic stress disorder: evaluating basic assumptions underlying the PTSD diagnosis. Psychol Rev. 2008;115(4):985-1011. [PMID:18954211] http://dx.doi.org/10.1037/a0013397

42. Flor H, Birbaumer N. Psychophysiological methods in the assessment and treatment of chronic musculoskeletal pain. In: Carlson JG, Seifert AR, Birbaumer N, editors. Clinical applied psychophysiology. New York (NY): Plenum Press; 1994. p. 171-84.

43. Rabe S, Dörfel D, Zöllner T, Maercker A, Karl A. Cardiovascular correlates of motor vehicle accident related posttraumatic stress disorder and its successful treatment. Appl Psychophysiol Biofeedback. 2006;31(4):315-30.

[PMID:17094031]

http://dx.doi.org/10.1007/s10484-006-9027-1

44. Casada JH, Roache JD. Dissociation of physiology and behavior in PTSD. Int J Psychophysiol. 2006;62(2):243-48. [PMID:16814888] http://dx.doi.org/10.1016/j.ijpsycho.2006.04.005

45. Lang PJ. The application of psychophysiological methods to the study of psychotherapy and behavior modification. In: Bergin AE, Garfield SL, editors. Handbook of psychotherapy and behavior change: An empirical analysis. New York (NY): Wiley; 1971. p. 75-125.

46. Denver JW, Reed SF, Porges SW. Methodological issues in the quantification of respiratory sinus arrhythmia. Biol Psychol. 2007;74(2):286-94. [PMID:17067734] http://dx.doi.org/10.1016/j.biopsycho.2005.09.005

47. Porges SW. Orienting in a defensive world: mammalian modifications of our evolutionary heritage. A polyvagal theory. Psychophysiology. 1995;32(4):301-18.

[PMID:7652107] http://dx.doi.org/10.1111/j.1469-8986.1995.tb01213.x

48. Porges SW. Emotion: an evolutionary by-product of the neural regulation of the autonomic nervous system. Ann N Y Acad Sci. 1997;807:62-77. [PMID:9071344] http://dx.doi.org/10.1111/j.1749-6632.1997.tb51913.x

49. Porges SW. Neuroception: a subconscious system for detecting threat and safety. Zero to Three. Bulletin of the National Center for Clinical Infant Programs. 2004;24(5): 19-24.

50. Porges SW. The polyvagal perspective. Biol Psychol. 2007;74(2):116-43. [PMID:17049418] http://dx.doi.org/10.1016/j.biopsycho.2006.06.009

51. Porges SW. Reciprocal influences between body and brain in the perception and expression of affect: A polyvagal perspective. In: Fosha D, Siegel DJ, Solomon MF, editors. The healing power of emotion: Affective neuroscience, development, and clinical practice. New York (NY): W. W. Norton; 2009. p. 27-54.
52. Porges SW. The polyvagal theory: new insights into adaptive reactions of the autonomic nervous system. Cleve Clin J Med. 2009;76(Suppl 2):S86-90. [PMID:19376991] http://dx.doi.org/10.3949/ccjm.76.s2.17

53. Bouton ME, Bolles RC. Role of conditioned contextual stimuli in reinstatement of extinguished fear. J Exp Psychol Anim Behav Process. 1979;5(4):368-78. [PMID:528893] http://dx.doi.org/10.1037/0097-7403.5.4.368

54. Bouton ME, Bolles RC. Contextual control of the extinction of conditioned fear. Learn Motiv. 1979;10(4):445-66. http://dx.doi.org/10.1016/0023-9690(79)90057-2

55. Grillon C, Morgan CA 3rd. Fear-potentiated startle conditioning to explicit and contextual cues in Gulf war veterans with posttraumatic stress disorder. J Abnorm Psychol. 1999;108(1):134-42. [PMID:10066999] http://dx.doi.org/10.1037/0021-843X.108.1.134

56. Wolpe J. Psychotherapy by reciprocal inhibition. Stanford (CA): Stanford University Press; 1958.

57. Seifert AR, Lubar JF. Reduction of epileptic seizures through EEG biofeedback training. Biol Psychol. 1975; 3(3):157-84. [PMID:812560] http://dx.doi.org/10.1016/0301-0511(75)90033-2

58. Birbaumer N, Rockstroh B, Elbert T, Wolf P, DüchtingRöth A, Reker M, Daum I, Lutzenberger W, Dichgans J. Biofeedback of slow cortical potentials in epilepsy. In: Carlson JG, Seifert AR, Birbaumer N, editors. Clinical applied psychophysiology. New York (NY): Plenum Press; 1994. p. 29-42.

59. Walker JE. Recent advances in quantitative EEG as an aid to diagnosis and as a guide to neurofeedback training for cortical hypofunctions, hyperfunctions, disconnections, and hyperconnections: improving efficacy in complicated neurological and psychological disorders. Appl Psychophysiol Biofeedback. 2010;35(1):25-27. [PMID:19830549] http://dx.doi.org/10.1007/s10484-009-9107-0

60. De Houwer J. Why the cognitive approach in psychology would profit from a functional approach and vice versa. Perspect Psychol Sci. 2011;6(2):202-9. http://dx.doi.org/10.1177/1745691611400238

61. Morganstern KP. Implosive therapy and flooding procedures: a critical review. Psychol Bull. 1973;79(5):318-34. [PMID:4574837] http://dx.doi.org/10.1037/h0034571

62. Norrholm SD, Vervliet B, Jovanovic T, Boshoven W, Myers KM, Davis M, Rothbaum B, Duncan EJ. Timing of extinction relative to acquisition: a parametric analysis of fear extinction in humans. Behav Neurosci. 2008;122(5): 1016-30. [PMID:18823159] http://dx.doi.org/10.1037/a0012604

63. Blechert J, Michael T, Vriends N, Margraf J, Wilhelm FH. Fear conditioning in posttraumatic stress disorder: evidence for delayed extinction of autonomic, experiential, 
and behavioural responses. Behav Res Ther. 2007; 45(9):2019-33. [PMID:17442266]

http://dx.doi.org/10.1016/j.brat.2007.02.012

64. Blanchard EB, Hickling EJ, Forneris CA, Taylor AE, Buckley TC, Loos WR, Jaccard J. Prediction of remission of acute posttraumatic stress disorder in motor vehicle accident victims. J Trauma Stress. 1997;10(2):215-34. [PMID:9136089]

http://dx.doi.org/10.1002/jts.2490100205

Submitted for publication November 8, 2011. Accepted in revised form January 30, 2012.
This article and any supplementary material should be cited as follows:

Seifert AR. Absence of verbal recall or memory for symptom acquisition in fear and trauma exposure: A conceptual case for fear conditioning and learned nonuse in assessment and treatment. J Rehabil Res Dev. 2012; 49(8):1209-20.

http://dx.doi.org/10.1682/JRRD.2011.11.0214

ResearcherID: A. Ronald Seifert, PhD: G-4258-2011

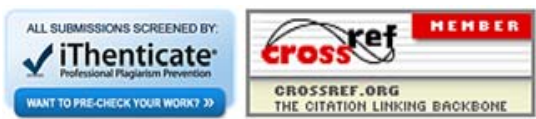


